\title{
CHEMICAL MODIFICATION IN KARANJA OIL FOR BIOLUBRICANT INDUSTRIAL APPLICATIONS
}

\author{
*Chauhan Prerna Singh, Dr. V.K. Chhibber \\ Uttarakhand Technical University, Dehradun, (U.K.) \\ *Corresponding Author's Email Id: prernachauhan26@gmail.com
}

\begin{abstract}
:
Vegetable oils are perceived to be alternatives to mineral oils for lubricant base oils because of certain inherent technical properties and their biodegradability. Vegetables oils with high oleic contents are considered to be the best alternative to substitute conventional mineral oil-based lubricating oils and synthetic esters. This paper mainly reveals about extraction of oil from dry karanja seeds and study of its composition and physic-chemical properties and further its modification into trimesters to improve the oxidation and cold flow behavior. Here, we report the oxirane ring opening of epoxidized karanja oil using behenic acid and $p$-toluenesulfonic acid (PTSA) as catalyst followed by esterification reaction with octanol and 2 ethylhexanol to form diesters. The remaining free hydroxyl group was reacted with oleic and stearic acid to give triesters. The oil before modification has viscosity index, pour point and flash point of $172,-9^{\circ} \mathrm{C}$ and $212^{\circ} \mathrm{C}$ and after modification it was $194 \mathrm{cp},-36^{\circ} \mathrm{C}$ and $307^{\circ} \mathrm{C}$ respectively, which can be easily used as metal working lubricant, hydraulic fluid turbine oil, refrigeration oil and food processing lubricant. The structures of the products were confirmed by FTIR, ${ }^{1} \mathrm{H}-$ and ${ }^{13} \mathrm{C}-\mathrm{NMR}$.

Key words: karanja oil, epoxidation, oxidation stability, biolubricants.
\end{abstract}

\section{INTRODUCTION}

A critical appraisal is made of the applications of vegetable oils, the fatty esters complex and synthetic esters as rapidly biodegradable and non-toxic lubricants and fuels in the developed countries of America, Europe, and Asia. As the stock of fossil fuels diminishing, throughout the world and demands for energy based comforts and mobility ever increasing, so there is a need to increase bio lubricant production .Bio lubricant is an alternative lubricant different from mineral oil lubricant as it is prepared from non-conventional energy resources and is non toxic, biodegradable and eco friendly. India has great potential for production of bio lubricant from non-edible oilseeds. The promising non-edible sources in India are Pongamia pinnata (Karanja), Melia azadirachta (Neem), Madhuca indica (Mahua), Linseed (Linium usitatissimum), Castor oil (Ricinus communis), Rice Bran oil (Oryza sativa). Bio lubricants are being given serious consideration as potential sources of energy in the future, particularly in developing countries like India. Increasing environment awareness and the desire to preserve endangered species, which were indiscriminately killed for their oils and fats ${ }^{1,2}$. Over $60 \%$ of the lubricants are lost to the environment ${ }^{3}$.There is an increasing concern for environmental pollution from excessive petroleum based lubricants use and their disposal especially in lost lubrication, military applications, and in outdoor activities such as forestry, mining, railroads, dredging, fishing and agriculture hydraulic systems ${ }^{4}$. The country is endowed with more than 100 species of tree born-edible oil seeds occurring in the country ${ }^{5}$. Vegetable oils with high oleic content are considered to be potential candidates to substitute conventional mineral oil-based lubricating oils and synthetic esters ${ }^{6}$. Vegetable oils are preferred over synthetic fluids because they are renewable resources and cheaper ${ }^{7}$. Furthermore, vegetable oils lubricants are biodegradable and non-toxic, unlike conventional mineralbased oils ${ }^{8}$. They have very low volatility due to the high molecular weight of the triacylglycerol molecule and have narrow range of viscosity changes with temperature. Polar ester groups are able to adhere to metal surfaces, and therefore, possess good boundary lubrication properties. In addition, vegetable oils have high solubilizing power for polar contaminants and additive molecules 9 Biodegradable greases ${ }^{10}$ are good candidates for foodprocessing and water-management machinery. On the other hand, vegetable oils have poor oxidative stability primarily due to the presence of bis allylic protons and are highly susceptible to radical attack and subsequently undergo oxidative degradation to form polar oxy compounds. This phenomena result in insoluble deposits and increases in oil acidity and viscosity ${ }^{11}$. Vegetable oil also shows poor corrosion protection. The presence of ester functionality renders these oils susceptible to hydrolytic breakdown ${ }^{12}$. Therefore, contamination with water in the form of emulsion must be prevented at every stage. Low temperature study has also shown that most vegetables oils undergo cloudiness, precipitation, poor flow, and solidification at $-10^{\circ} \mathrm{C}$ upon long-term exposure to cold temperature ${ }^{13}$ in sharp contrast to mineral oilbased fluids. These physical and chemical properties can be improved either using genetically modified oils or chemically modified oil with suitable combination of additives ${ }^{14}$. Plant species, which have $30 \%$ or more fixed oil in their seeds or kernel, have been identified ${ }^{15}$.Traditionally the collection and selling of tree oilseeds was generally carried out by poor people for use as fuel for lightening. Presently there is an extended use of these oils in soaps, shampoos, varnishes, bio lubricants, candles, cosmetics, biodiesel, etc. However, the current utilization of non-edible oilseeds is very low. Bio lubricant is a product, other than food or feed, substantially composed of certain biological products agricultural materials or forestry materials. The product is used in place of a petroleum based lubricant.

\section{Biodegradability:}


American society of testing and materials (ASTM) defines biodegradable as "capable of undergoing decomposition into carbon dioxide, methane, water are less later, inorganic compounds, or biomass in which the predominant mechanism is the enzymatic action of microorganisms that can be measured by standardized tests, in a specified period of time, reflecting available disposal conditions. Biodegradability ${ }^{16}$ is the ability of matter to be decomposed by several microorganisms it can also be defined as assessing the degree of appropriateness of a specific lubricant through various biodegradability tests such as CEC-L-33-A-94. Biodegradable lubricants are less toxic and remain harmless in various applications from automotive to industrial due to their capability of maintaining maximum protection to nature and minimum health hazard to humans. They remain eco-friendly and biodegradable in its whole cycle from production to application and degradation by microorganisms .Due to biodegradable in nature they can be renewed and provide a better option with bright future aspects to be adopted as a next generation lubrication solution . They can be proved as a source of income and employment for peoples or both. Research and development is worldwide done on utilization of non edible oils for the production of biodiesel, bio-lubes, additives for lubricating oils, saturated and unsaturated alcohols and fatty acids and many other values added products .Technology for bio-lubricant such as Engine oils,2T Oils .Compressor Oils, Aviation Oil, Metal Working Fluids, Insulating Oil, Gear Oil, Hydraulic Oil, etc. are expected to be commercialized soon ${ }^{17}$. Bio lubricants must be used in priority for all applications where there is environmental risk. Vegetable oils are by their chemical nature long chain fatty acid tri esters of glycerol (triglyceride) and provide most of the desirable lubricantproperties such as good lubrication, load carrying capacity, anti-wear, high viscosity index, high flash point and low volatility ${ }^{18}$.

\section{MATERIALS AND METHODS}

\section{Materials: Oil Processing From Karanja Seeds}

A Karanja seed (Pongamia glabra) was brought from a local fodder shop in Dehradun, India. The seeds were grinded into fine particles and by use of $n$-hexane solvent oil was extracted by the use of soxhlet apparatus. All other chemicals and reagents were sold from Central Drug House (P) Ltd, New Delhi. Extraction is one of the key processing steps in recovering oils contained in seeds. Mechanical pressing ${ }^{19}$ is the simplest method of extraction, however, needs no extraction medium. It has been traditionally applied to the extraction of oils from oil seeds; the only equipment needed is a hydraulic press.

\section{Extraction of Oil from Non-Edible Karanja Seeds and Its Purification}

Oil extraction can be done with or without seed coat, for Karanja utilization of a mechanical de hulling system (to remove the seed coat) can increase oil yield by 10 percent. By choosing efficient extraction methods the percentage yield of oil from non-edible seed can be increased by more than $5 \%$. In cold pressing $\left(<60^{\circ} \mathrm{C}\right)$, around $86-88 \%$ efficiency can be achieved, hot pressing $\left(110-120^{\circ} \mathrm{C}\right)$ can increase it to around $90 \%$.Solvent extraction methods enhances the efficiency up to $99 \%$. In solvent extraction method generally n-hexane or n-heptane solvent is employed ${ }^{20}$.

The oil is used by common people due to its low cost and easy availability. The fatty acid composition of karanja oil has been reported in Table- ${ }^{20}$. The kernels contain 27-39 percent of oil ${ }^{21}$. The oil yield is $18-22$ percent in ghanis and 24-27 percent in expellers. The fresh extracted oil is yellowish orange to brown, and rapidly darkens on storage. It has a disagreeable odour and bitter taste. Solvent extraction of expelled cake yields better quality light yellow oil. The theoretical potential of oil is estimated to be 135,000 tonnes, but the actual collection has been stagnant around 4000 to 6500 tons in the past eight years 22 . The present production of karanja oil approximately is 200 million tons per annum ${ }^{23}$.

Table 1: Fatty acid composition of karanja oil determined by GCMS Method

\begin{tabular}{|l|l|l|l|}
\hline Fatty Acid & Molecular Formula & Percentage & Structure \\
\hline Palmitic Acid & $\mathrm{C} 16 \mathrm{H} 32 \mathrm{O} 2$ & 11.65 & $\mathrm{CH} 3(\mathrm{CH} 2) 14 \mathrm{COOH}$ \\
\hline Stearic Acid & $\mathrm{C} 18 \mathrm{H} 36 \mathrm{O} 2$ & 7.5 & $\mathrm{CH} 3(\mathrm{CH} 2) 16 \mathrm{COOH}$ \\
\hline Oleic Acid & $\mathrm{C} 18 \mathrm{H} 34 \mathrm{O} 2$ & 51.59 & $\mathrm{CH}(\mathrm{CH} 2) 14(\mathrm{CH}=\mathrm{CH}) \mathrm{COOH}$ \\
\hline Linoleic Acid & $\mathrm{C} 18 \mathrm{H} 32 \mathrm{O} 2$ & 16.64 & $\mathrm{CH} 3(\mathrm{CH} 2) 12(\mathrm{CH}=\mathrm{CH}) 2 \mathrm{COOH}$ \\
\hline Eicosanoic Acid & $\mathrm{C} 20 \mathrm{H} 40 \mathrm{O} 2$ & 1.35 & $\mathrm{CH} 3(\mathrm{CH} 2) 18 \mathrm{COOH}$ \\
\hline Dosocasnoic Acid & $\mathrm{C} 22 \mathrm{H} 44 \mathrm{O} 2$ & 4.45 & $\mathrm{CH} 3(\mathrm{CH} 2) 20 \mathrm{COOH}$ \\
\hline Tretracosanoic Acid & $\mathrm{C} 24 \mathrm{H} 48 \mathrm{O} 2$ & 1.09 & $\mathrm{CH} 3(\mathrm{CH} 2) 22 \mathrm{COOH}$ \\
\hline Residual & & 6.83 & \\
\hline
\end{tabular}


The Physico-chemical properties of karanja oil are shown in the table-2 given below:

Table 2: Physico-chemical properties of karanja oil

\begin{tabular}{|c|c|}
\hline Characteristics & Karanja Oil \\
\hline Kinematic Viscosity, cST & \\
$40^{\circ} \mathrm{C}$ & 43.42 \\
$100^{\circ} \mathrm{C}$ & 8.35 \\
\hline Viscosity Index & 172 \\
\hline Iodine Value & 78 \\
\hline Saponification Value & 179 \\
mgKOH/gm & \\
\hline Acid Value mg KOH/gm & 22 \\
\hline Pour Point ${ }^{\circ} \mathrm{C}$ & -9 \\
\hline
\end{tabular}

Karanja seeds are good source of oleic acid as its percentage is 51.59 and are thermally stable than poly unsaturated fats, and therefore are highly desired component in vegetable oils for lubricant applications. Karanja can be successfully propagated through seeds and cuttings ${ }^{24}$. Modification of karanja oil through chemical processing to improve oxidation stability and low temperature fluidity is made possible by combining it with chemical additive and hence such chemical modification made to improve the cold flow behavior of vegetable oils for the use as bio lubricant base oil.

\section{Synthesis of Epoxidized Oleic Acid (1):}

Hydrogen peroxide solution $\left(30 \%\right.$ in $\left.\mathrm{H}_{2} \mathrm{O}, 9 \mathrm{ml}\right)$ was added slowly into stirred solution of oleic acid $(90 \%$, $10 \mathrm{gm})$ in formic acid $(88 \%, 9 \mathrm{ml})$ at $4^{0} \mathrm{C}$ (ice bath). Then the reaction proceeds at room temperature with vigorous stirring (900rpm) until formation of a white, powdery solid was noticed in the reaction vessel for 2-5 hours. The solid was collected via vaccum filteration, washed with water (chilled, $3 \times 10 \mathrm{ml}$ ), and placed for $12 \mathrm{hrs}$ under vaccum to provide epoxidized oleic acid as a colorless, powdery solid.

\section{Synthesis of 9(10) hydroxy-10(9)-behnyloxystearic Acid (2):}

Epoxidized oleic acid (1, 31gm) and 5gm of PTSA by dissolving it in toluene in $250 \mathrm{ml}$ three-neck flask equipped with a cooler, dropping funnel and thermometer. The mixture was kept at $50^{\circ} \mathrm{C}$. Behenic acid $(6 \mathrm{gm})$ was added during $1.5 \mathrm{hrs}$ in order to keep the reaction mixture temperature under $70-80^{\circ} \mathrm{C}$. The reaction mixture was subsequently heated to $90-100^{\circ} \mathrm{C}$ and refluxed for $3 \mathrm{hrs}$ at this temperature range. After reaction termination, the heating was stopped and the mixture was left to stand overnight at ambient room temperature. The mixture was then washed with water, the organic layer was dried over anhydrous magnesium sulfate and the solvent was removed using vaccum evaporator to give the desired product.

\section{Synthesis of Alkyl 9 (10)-hydroxy-10 behnyloxysterate ( 3 and 4$)$ :}

(9)-

Sulfuric acid (conc. $\mathrm{H}_{2} \mathrm{SO}_{4}, 10 \mathrm{~mol} \%$ ) was added to a solution of 9(10)-hydroxy-10(9)-acyloxystearic acid $(2,1 \mathrm{gm})$ in either $3.35 \mathrm{ml}$ octanol or $3.35 \mathrm{ml} \mathrm{2-}$ ethylhexanol. The suspension was heated with stirring at $60^{\circ} \mathrm{C}$ for 10 hours. Hexanes $(5 \mathrm{ml})$ was then added, and the (c) 2011, JDDT. All Rights Reserved solution was washed with $\mathrm{NaHCO}_{3}$ (sat. aq., 1x $0.5 \mathrm{ml}$ ) and brine $(2 \times 1 \mathrm{ml})$, dried $9\left(\mathrm{MgSO}_{4}\right)$, filtered, concentrated and placed under vaccum for 6-7 hours to yield the desired compounds of (3) and (4), respectively.

\section{Synthesis of Modified Triesters (5 and 6):}

To a solution of alkyl 9(10)-hydroxy-10(9)behnyloxystrearate ( 3 and 4, 10gm) and sulfuric acid (10\% $\mathrm{H}_{2} \mathrm{SO}_{4}$ ) in a two-neck round bottom flask equipped with a magnetic stir bar at room temperature; then the reaction mixture was refluxed with stirring for $10 \mathrm{hrs}$. After the reaction was transferred to a separating funnel, the lower aqueous phase was removed, and hexane $(20 \mathrm{ml})$ was added to the upper oily phase. The organic phase was then washed with $\mathrm{NaHCO}_{3}$ (sat. aq., 2x $5 \mathrm{ml}$ ) and brine $(2 \times 5 \mathrm{ml})$, dried $9\left(\mathrm{MgSO}_{4}\right)$, filtered, concentrated and placed under high vaccum for 5-6 hours to provide the trimesters (5and6).

\section{Instrumentation:}

Fourier transform infared (FTIR) spectra were recorded on a Perkin Elmer Infrared Spectrophotometer. The ${ }^{1} \mathrm{H}$ - and ${ }^{13} \mathrm{C}-\mathrm{NMR}$ spectrum were recorded on a JNM-ECP 400 spectrometer $\left(400 \mathrm{MHz}{ }^{1} \mathrm{H} / 100.61 \mathrm{MHz}^{13} \mathrm{C}\right.$ ) using DMSO$\mathrm{d}_{6}$ as a solvent in all experiments. All the physical properties analyses were performed according to the standard methods for flash point, pour point and viscosity index. Viscosity reading is in centipoises (cp) and the unit is in mPa's (multipascal second).

\section{RESULTS AND DISCUSSION}

\section{Synthesis:}

Here reaction proceeds with epoxidation of oleic acid to yield epoxidized oleic acid to yield epoxidized oleic acid ${ }^{25}$.Then the oxirane ring was opened by using behenic acid and $p$ - toluenesulfonic acid (PTSA) as catalyst ${ }^{26}$. From above raction we get 9 (10) - hydroxy-10(9)behnyloxystearic acid from 9, 10-epoxyoleic acid with yield $66 \%$. Esterification of the oleic acid carbonyl was done by using octanol and 2-ethylhexanol in order to prepare alkyl 9, (10)-hydroxy-10(9)-behnyloxystearate (3 and4) with a yield $73 \%$ and $65 \%$, respectively.

The two prepared diesters of 9, 10-hydroxy-acyloxystearic acid were used as a key for the synthesis of modified trimesters-derivatives by esterification of the hydroxyl diester groups with either oleic acid or stearic acid. The yields are summarized in Table 6.

\section{Infra-Red Spectroscopy:}

The structures of the synthesized compounds were confirmed were confirmed using Fourier-Transformed Infrared (FTIR) spectroscopy. The characteristic signals in the FTIR spectrum of epoxidized oleic acid (1) at 830, $845 \mathrm{~cm}^{-1}$ correspond to quaternary carbons of the oxirane ring ${ }^{27}$ and the signals at 2987 and $2865 \mathrm{~cm}^{-1}$ correspond to aliphatic carbons in the molecules. In mono-ester product (2) the bands at 1738 and $1710 \mathrm{~cm}^{-1}$ due to $\mathrm{C}=\mathrm{O}$ stretching vibrations of ester and carboxylic acid moieties confirm the success of oxirane ring opening step. Furthermore, the most characteristic evidence confirms trimester formation was the disappearance of $\mathrm{OH}$ stretching vibration around $3400 \mathrm{~cm}^{-1}$. Other characteristic FTIR data are summarized in Table 3. 
Epoxidation: This method gives partially saturated derivatives with oxygen.

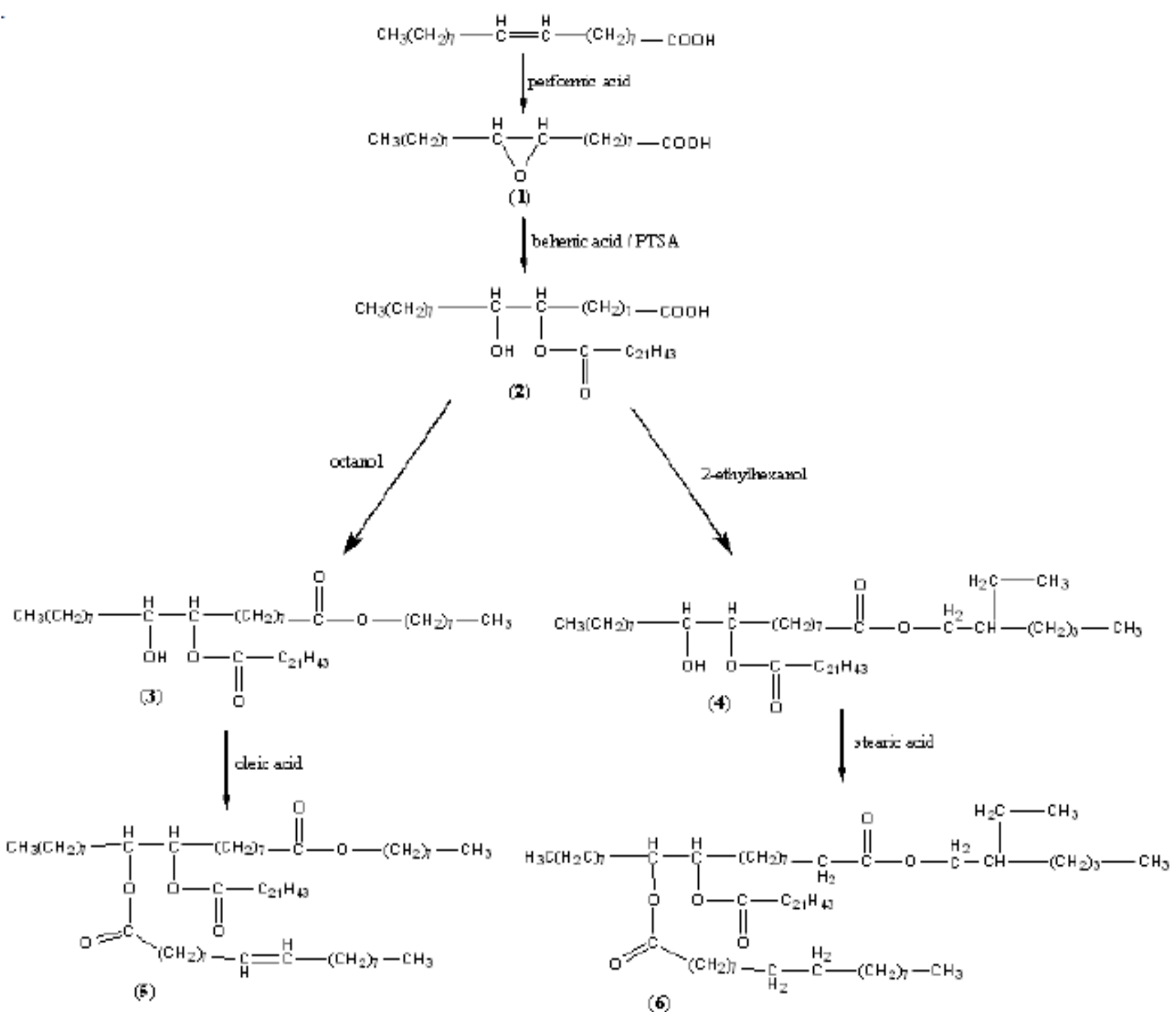

Figure 1: Synthesis for Compound 1-6

Table 3: Characteristic FTIR absorption data of compounds (1-6)

\begin{tabular}{lllll}
\hline compound & $v(0-\mathrm{H})$ & $v(\mathrm{C}-\mathrm{H})$ aliphatic & $v(\mathrm{C}=0)$ & $v(-\mathrm{C}-0-\mathrm{C})$ \\
\hline 1 & 3425 & 2987,2865 & 1708 & 830,845 \\
2 & 3441 & 2946,2872 & 1738,1710 & - \\
3 & 3453 & 2947,2822 & 1730 & - \\
4 & 3412 & 2943,2826 & 1727 & - \\
5 & - & 2937,2891 & 1733 & - \\
6 & - & 2982,2865 & 1734 & - \\
\hline
\end{tabular}

\section{NMR Spectroscopy:}

All compounds displayed good solubility in DMSO. The nuclear magnetic resonance spectral data gave additional support for the composition of the compounds. The observed changes are evidences of the reaction had happened because the chemical shift of a compound is heavily depended on its electronic environment. The ${ }^{1} \mathrm{H}$ NMR spectra of the trimester compounds (5 and6) confirmed the disappearance of $\mathrm{OH}$ signal at about 9.409.65 ppm. Furthermore, at about $\delta$ 2.15-3.57 ppm resonance the protons signals of the aliphatic $-\mathrm{CH}_{2}-$ were appeared for the prepared compounds ${ }^{28}$. Other characteristic data are tabulated in table 4.

The ${ }^{13} \mathrm{C}-\mathrm{NMR}$ data of the prepared products are presentable in Table- 4 . The $\mathrm{C}=\mathrm{O}$ resonance group of the products appear at about $170.36-174.62 \mathrm{ppm}$. It is most likely that shift is due to the decrease of electron density at carbon atoms when oxygen is bonded to it ${ }^{28}$. In the case of compounds $(2,4)$ there are two signals while in with compounds (5 and 6) there are three signals in this range. These results were in agreement with the proposed structures which given to these compounds. 
Table 4: ${ }^{1} \mathrm{H}$-NMR spectral $(\delta, \mathrm{ppm})$ data of prepared products

\begin{tabular}{llllll}
\hline compound & $-\mathrm{CH}_{3}$ & $\mathrm{CH}_{2}$ aliphatic & & & \\
& & & & & \\
& & & & & \\
\hline 1 & $1.13-1.54$ & $2.30-3.52$ & $4.50-5.37$ & - & 8.55 \\
2 & $1.24-1.62$ & $2.28-3.57$ & $4.47-5.40$ & - & $8.51,9.25$ \\
3 & $1.53-1.76$ & $2.15-3.52$ & $4.53-5.40$ & - & $8.52,9.32$ \\
4 & $1.23-1.80$ & $2.40-3.53$ & $4.32-5.35$ & $5.29,5.63$ & - \\
5 & $1.21-1.53$ & $2.37-3.56$ & $4.42-5.44$ & - & - \\
6 & $1.19-1.67$ & $2.31-3.55$ & $4.50-5.41$ & & - \\
\hline
\end{tabular}

Table 5: ${ }^{13} \mathrm{C}-\mathrm{NMR}$ spectral $(\delta, \mathrm{ppm})$ data of prepared products

\begin{tabular}{llllll}
\hline compound & $-\mathrm{CH}_{3}$ & $-\mathrm{CH}_{2}$ & & \\
& & & & & \\
& & & & & \\
\hline 1 & $22.56-24.34$ & $26.56-41.30$ & $60.67,62.53$ & - & 172.67 \\
2 & $21.32-24.78$ & $26.45-40.65$ & $60.62,62.55$ & - & $171.43,174.62$ \\
3 & $22.67-24.87$ & $26.43-40.51$ & $60.60,62.54$ & - & $170.86,173.56$ \\
4 & $20.85-24.11$ & $26.50-40.34$ & $60.56,62.50$ & - & $170.86,173.56$ \\
5 & $22.35-25.12$ & $26.51-40.54$ & $60.56,62.47$ & $62.42,64.32$ & $171.43,173.14,174.08$ \\
6 & $22.50-24.52$ & $26.45-40.28$ & 60.5762 .53 & - & $171.54,172.48,174.60$ \\
\hline
\end{tabular}

\section{Effect of chemical Modification on Physical properties:}

There is an important fact in determining how well oil will behave as a potential lubricant is to evaluate the pour point (PP). The low temperature flow property of vegetable oils is extremely poor and this limits their use at low operating temperatures especially as automotive and industrial fluids. In the high oleic oils removal of polyunsaturation (low unsaturation numbers) results in improved cold flow property due to reduction in saturated fatty acids. However, the high oleic oils are still limited in their use in low temperature applications ${ }^{6}$.

The prepared compounds (2-6) described above were screened for low-temperature behavior through determination of both $\mathrm{CP}$ and PP. Modified trimester exhibited a PP of $-36^{\circ} \mathrm{C}$ (Table-6), which is an improvement over that of other compounds. As, expected, as the chain length of the ester increased, a corresponding improvement in PP is observed, which may be due to the greater ability of the longer-chain esters to more effectively disrupt macrocrystalline formation at reduced temperature. A positive effect on the low-temperature performance of the resultant products was observed when a branched alcohol, 2-ethyl hexanol, was used. For instance, compound (6) has PP of $-36^{\circ} \mathrm{C}$, whereas compound (5) has $\mathrm{PP}$ of $-31^{\circ} \mathrm{C}$. This improvement in $\mathrm{PP}$ is observed, which may be due to the greater ability of the branch-chain esters to more effectively disrupt macro crystalline formation at reduced temperatures.

Table 6: Pour point, Flash point, Viscosity values and Percentage Yield of prepared products

$\begin{array}{rcccc}\text { Compound } & \text { Pour point }\left({ }^{0} \mathrm{C}\right) & \text { Flash point }\left({ }^{0} \mathrm{C}\right) & \text { Viscosity }(\mathbf{c p}) & \text { Yield }(\% 0 \\ \text { 1. } & - & 140 & - & 72 \\ 2 . & - & 232 & - & 64 \\ \text { 3. } & -23 & 142 & 129 & 73 \\ \text { 4. } & -28 & 165 & 149 & 65 \\ 5 . & -31 & 176 & 159 & 87 \\ \text { 6. } & -36 & 307 & 194 & 92\end{array}$

Concerns over the discharge and accumulation of lubricants and fuels on land, water and air posing serious hazards to health and deleterious effects on the environment led to the framing of increasing stringent state policies discouraging the use of conventional petroleum based lubricants in several applications such as total loss lubricants, industrial lubricants for food processing, watermanagement machinery, two-stroke engine lubricants, etc. and encouraging their replacement with rapidly biodegradable lubricants of low toxicity [29, 30]. There are 
moves to replace mineral oil based lubricants in high powered diesel engine vehicles with low evaporation loss ester based lubricants in order to reduce particulate emissions which pose serious respiratory problems in large cities [31, 32]. Vegetable oils when used as renewable raw materials for new industrial products such as lubricants have been a great importance now a day because of the emphasis on environmental friendly lubricants is large in demand due to the rapid depletion of world fossil fuel reserves and increasing concern for environmental pollution from excessive mineral oil usage.

\section{CONCLUSIONS:}

In the present study, several basic trends were observed. The prepared compounds (2-6) exhibited the favorable cold-flow characteristics, as determined by PP. Compound (6) yielded the best performance with PP of $-36^{\circ} \mathrm{C}$. The presence of branching group at the head of the molecule will make it more effectively in disruption crystalline formation at reduced temperatures. These products can be efficiently utilized for bio based industrial materials, such as bio lubricants. Contaminated environment is expensive.
Conventional mineral oil based lubricants are extremely harmful for the biosphere when they get into the environment. Due to poor degradability mineral oils remain in the ecosystem for a long time. Even in case of high dilution the effect will be fatal (eco-toxicological effect). Higher amount will be required for elimination of contaminated ecosystem clearly. Eco friendly hydraulic oil, refrigerator oil, gear oil, motor oil, two stroke engine oils, lubricants for food processing and water management and disposal operations and eco-friendly greases for both general purpose and multipurpose should be widely used. Eco friendly biodegradable lubricants has to be immediately introduced in the market to replace the mineral oil and other non-biodegradable products currently in use in these countries to check rampant pollution caused by these lubricants. Edible oils in use in developed nations such as USA and European nations but in developing countries the production of edible oils are not sufficient. In a country like India, there are many plant species whose seeds remain unutilized and underutilized have been tried for biodiesel production. Non-edible oil seeds are the potential feedstock for production of bio lubricant in India.

\section{REFERENCES}

1. Murphy DJ. Engineering oil production in rapeseed and other oil crops. Trends in Biotechnology 1996; 14 206-213.

2. Lee M, Lenman M,Banas A, Bafor M, Schweizer M, Nilsson R, Lilgenberg C, Dahlquish A, Gummesom PO, Green A.Science $1998 ; 280 ; 915-918$

3. Gawrilow, I., 2004. Vegetable Oil usage in Lubricants. Inform 15: 702-705.

4. Jumat Salimon, Nadia Salih. Chemical Modification of Oleic Acid Oil for Biolubricant Industrial Applications. AIBAS, 4 (7): 1999-2003, 2010.

5. P.radhakrishna 2003.Tree borne oil seeds as a source for decentralized planning. Government of India, ministry of non-conventional energy sources, New delhi, India

6. Hwang,H., and S.Z. Erhan, 2001. Modification of Epoxidized Soyabean Oil for lubricant Formulations with improved Oxidized Stability and Low Pour Point. J. Am. Oil Chem. Soc., 78 : 1179-1184.

7. Adhvaryu, A., Z. Liu, and S.Z. Erhan, 2005. Synthesis of Nove Alkoxylated Triacylglycerols and Their Lubricant Base Oil Properties. Ind. Crops Prod., 21: 113-119.

8. Thames, S. F. and H. Yu, 1999. Cationic UV-Cured Coatings of Epoxide-Containing Vegetable Oils. Surf. Coat. Technology. 115:2-3.

9. Dinda, S., A.V. Patwardhan, V.V Goud and N.C. Pradhan, 2008 Epoxidation of cottonseed oil by aqueous hydrogen peroxide catalysed by liquid inorganic acids. Bioresource Techonology, 99: 3737-3744.

10. Cherry NA. Spilling the beans about castor oil and its derivatives. NLGI Spokesman 2000; 64(1):18-24.

11. Jayadasa, N.H., K.P. Nair and G. Ajithkumar, 2007. Tribiological evalution of coconut oil as an environment-friendly lubricant. Tribology International, 40:350-354.

12. Wua, X., X. Zhanga, S. Yangb. Chena and D. Wanga, 2000. The study of epoxidized rapeseed Oil used as a Potential Biodegradable Lubricant. J.Am. Oil Chem. Soc., 77(5): 561-563.

13. Schuster, H., L.A. Rios, P.P. Weckes. Hoelderich, 2008 Heterogeneous catalysts for the production of new lubricants with unique properties. Appl. Cat, A: General, 348: 266-270.

14. Moser, B.R., S.C.Cermak and T.A.Isbell, 2008. Valution of castor and Lesquerella Oil Derivatives as Additives in Biodiesel and Ultralow sulfur Diesel Fuels, Energy and Fuels, 22: 1349-1352.

15. Azam A.N.M., and Nahar N.M., 2005. Biomass and Bioenergy.2005 Article in press

16. Sustainable development planning executive summary Jorge alejandro delavega Lozano January 2007.

17. Vivek and A.K.Gupta Journal of Scientific and Industrial research vol63, January 2004, pp 39-47.
18. Garba b and sambo.as. (1995). Effect of some operating parameters on biogas production rate. Nigerian journal on renewable energy, 3: 3644.

19. M.K. Abu-Arabi, M.A. Allawzi, H.S. Al-Zoubi, A. Tamimi, Extraction of jojoba oil by pressing and leaching, Chem. Eng. J. 76 (2000)61-65 http://linkinghub.elsevier.com/retrieve/pii/S1385894799001199 doi:10.1016/S1385-8947(99)00119-9.

20. Katwal RPS, Soni PL. Indian Forester 2003; 129 (8):939-49.

21. Tree borne oilseeds, Khadi and Village Industries Commision, Bombay, 1978.

22. Menon, V.P., Private communication; Estimate by Association of minor oils and seeds development of India.

23. Saroj K. Padhi and R. K. Singh Non-edible oils as the potential source for the production of biodiesel in India; J. Chem. Pharm. Res., 2011, 3(2):39-49.

24. National oilseeds and vegetable oils development board, Ministry of agriculture, Govt of India, $6^{\text {th }}$ May 2008.

25. Salimon,J. and N.Salih, 2009 a. Improved low temperature properties of 2-Ethylhexyl 9(10)-Hydroxy-10(9)-Acyloxystearate derivatives. Eur.J.Sci.Res., 31(4): 583-591.

26. Salimon,J. and N.Salih, 2009 b. Oleic Acid Diesters: Synthesis, Characterization and low temperature properties. Eur.J.Sci. Res., 32(2): 216-222.

27. Erhan, S.Z., B.K. Sharma and J.M.Perez, 2006. Oxidation and low temperature stability of vegetable oil-based lubricants. Ind. Crops Prod., 24: 292-299.

28. Silverstein, R.M., G. Bassler and T. Morrill, 2005. Spectometric Identification of organic compounds. $7^{\text {th }}$ Edn., John-Wiley, New York.

29. Horner D. Recent trends in environment friendly lubricants. In Proceedings of the international Symposium on fuels and Lubricants, New Delhi, 10-12 March 2000; 753-766.

30. Mang T, Bhatia. Environment friendly biodegradable lube base oilsTechnical and environmental trends in the European market. In Advances in production and application of Lube Base Stocks: Proceedings of the International Symposium on production and Application of Lube Base Stocks. Tata McGraw Hill: New Delhi, 1994; 66-80.

31. Legsia I, Picek M, Nahal K. Some experience with biodegradable lubricants. $10^{\text {th }}$ International Colloquium, Tribology, Technische Akademie Esslingen, January 1996; 861-870.

32. Salkeld JA, Taylor PJ, Fitton N, Sinha S, Diddi D. Synthetic lubricant base fulids :global market trends. In Proceedings of the International Symposium on Fuels and Lubricants, New Delhi, S10-12 March 2000; 113-118 